\title{
Regeneration properties of a Populus euphratica riparian forest located in the vicinity of the Ejina Oasis, Inner Mongolia, China
}

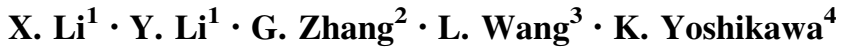

Received: 4 March 2014/Revised: 5 May 2016/Accepted: 23 May 2016/Published online: 28 July 2016

(c) The Author(s) 2016. This article is published with open access at Springerlink.com

\begin{abstract}
To explore the regeneration properties of a Populus euphratica Oliv. forest under unstable environmental conditions, we performed replicate censuses to determine the sapling dynamics of a $P$. euphratica population in the vicinity of the Ejina Oasis (Inner Mongolia). Even when the stands were established on riverside flatland, we detected slight variations in ground levels and salt concentrations. Due to leaching by flood water, the salinity of topsoil was lower in the riverbed than on the riverbank. Newly recruited saplings grew on riverbanks with highsalinity soil. Saplings were distributed over a wide area via fluctuating water levels, and those growing where salt levels were relatively low were able to grow more easily and become canopy trees. Small individuals comprise a sapling bank on the forest floor that is relatively stable. The dieback of larger saplings results in few reaching a height of more than $2 \mathrm{~m}$. The growth of saplings (including new recruits) is balanced by the death of smaller saplings and the dieback of larger saplings. Individual saplings persist
\end{abstract}

X. Li

xiaogang841025@yahoo.co.jp

K. Yoshikawa

kenchan@cc.okayama-u.ac.jp

1 College of Forestry, Agricultural University of Hebei, Baoding 071000, Hebei, China

2 College of Forestry, Inner Mongolia Agricultural University, Hohhot 010018, Inner Mongolia, China

3 College of Ecology and Environmental Science, Inner Mongolia Agricultural University, Hohhot 010018, Inner Mongolia, China

4 Graduate School of Environmental and Life Science, Okayama University, 1-1-1 Tsushima-naka, Okayama 700-8530, Japan for about 4 years on the forest floor. In summary, hydrological events coupled with soil conditions may drive vegetation distribution patterns in riparian areas in arid regions. $P$. euphratica forests regenerate via a sapling bank rather than a seed bank. Yearly fluctuations in water flow facilitate the spread of the sapling bank, which guarantees regeneration of the forest. Dieback through partial defoliation is a mechanism used by saplings to escape adverse conditions, thereby maintaining a stable state in arid regions.

Keywords Sapling dynamic · Ground level · Soil salinity · Sapling bank · Dieback

\section{Introduction}

Populus euphratica Oliv. is a species of Salicaceae that forms riparian forests in arid and semiarid regions extending from central and western Asia to North Africa and southern Europe. Mature trees usually reach 10-18 m in height. Regeneration is both sexual and asexual. Large numbers of small seeds are shed over several months (July-September) and germinate on freshly deposited sites formed by river floods in the summer (Thevs et al. 2008). Sprouts also grow from lateral roots, which spread in the surface soil layer within $20 \mathrm{~cm}$ below the surface and can extend up to $40 \mathrm{~m}$ from the parent tree (Wiehle et al. 2009).

P. euphratica forests in arid regions are sustained by rivers and groundwater, and regeneration is largely dependent on river flow (Hua 2003; Thevs et al. 2008; Zhu et al. 2012). The volume of flowing water fluctuates depending on weather conditions in the upper reaches of the rivers, as is common in drylands, and it is also under the 
influence of intensive agricultural production ( $\mathrm{Li}$ et al. 2000; Zhao et al. 2007; Haney et al. 2008). Along the lowest reaches of the Heihe River (Ejina Oasis), which originates in the Qilian Mountains and flows into the West and East Juyanhai Lakes, large riparian $P$. euphratica forests have become established. However, because several reservoirs have been built in the middle reaches of the river to support a growing human population, the amount of water supplied to the Ejina Oasis has declined year by year. In addition, local people have over-cultivated and overgrazed animals in these $P$. euphratica forests for many years. As a result, most of the P. euphratica forests in the Ejina Oasis have been negatively impacted and failed to regenerate either sexually or asexually (Cao et al. 2012). Successful regeneration is essential for a forest to construct a good structure to stay healthy, and restore and maintain its dynamic stability (D'Amato et al. 2009; Gauthier et al. 2015; Nyland et al. 2006), so it is important and necessary to understand the regeneration of $P$. euphratica.

Tree regeneration under a canopy layer depends on the establishment of recruits under newly opened canopy gaps before the immigration of other plant species. However, the seeds of $P$. euphratica retain the ability to germinate for only 1 week (Zhang et al. 2005), and germination is limited to the margins of flowing water or in shallow puddles, which may not always be located under canopy gaps. Suckers thus seem to be an effective strategy to close gaps between germination rows and contiguous forest (Wiehle et al. 2009). Regeneration by seeds is rare for a $P$. euphratica forest. The maintenance of a sapling bank under a stable canopy (rather than a seed bank) represents an effective regeneration mechanism for some tree species with intermittent production of small short-lived seeds (Hara 1987), which may be the case with P. euphratica. To elucidate how $P$. euphratica forests maintain themselves under unreliable conditions, it is necessary to understand how they attain stability via their two regeneration strategies. Barsoum (2002) studied the sexual and asexual regeneration strategies of Populus nigra L. var. betulifolia and Salix alba L. var. alba, which are like P. euphratica in having two regeneration strategies, and found that sexual and asexual regeneration were spatiotemporally different and could be affected by different environmental conditions, such as unseasonal floods and land elevation. Thevs et al. (2008) found that the successful establishment of $P$. euphratica seedlings was restricted to germination events as it depended highly on flood events during the following year. Flood is a main factor in the seedling germination and establishment of $P$. euphratica.

Although many researchers have focused on the regeneration of $P$. euphratica, knowledge of how its saplings guarantee the stability of its forests is lacking. Therefore, we investigated the stand structure and dynamics of a relatively stable $P$. euphratica forest in the Ejina Oasis to elucidate the temporal and spatial interactions between saplings and canopy trees, while focusing on the dynamics of saplings; we also determined the effects of site conditions on the spatial structure of these riparian stands.

\section{Materials and methods}

\section{Study area}

A natural forest of $P$. euphratica, located in the lower reaches of the Heihe River (Ejina County, Inner Mongolia Autonomous Region, China; $39^{\circ} 52^{\prime}-42^{\circ} 47^{\prime} \mathrm{N}, 97^{\circ} 10^{\prime}-$ $103^{\circ} 7^{\prime}$ E; Fig. 1) where typical hyperarid desert conditions prevail, was selected as the study area. Mean annual precipitation and mean annual potential evapotranspiration are 40 and $4200 \mathrm{~mm}$, respectively (Zhao et al. 2004), and thus the riparian forest in Ejina Oasis is largely dependent on the Heihe River as a source of water. More than 60-70 \% of the rainfall falls between July and September (Wen et al. 2005), and the basin elevation ranges from 898 to $1598 \mathrm{~m}$ above sea level (Wen et al. 2005).

\section{Experimental plot}

A $100 \times 100-m$ permanent experimental plot was established in the western sector of the Ejina Oasis in 2005 (Fig. 1). Elevation and topsoil electrical conductivity (EC) were determined in 2010 using a mini-compass and an EC meter (Conductivity Meter-14; HORIBA, Kyoto), respectively.

\section{Tree census}

Tree censuses were carried out annually during the period 2009-2012. All trees were numbered and their coordinates determined. In 2009, the heights of dead and living trees, diameters at breast height, and crown projection areas were measured. From 2010 onward, newly emerged individuals were numbered and the same measurements were made. Trees shorter than $2 \mathrm{~m}$ were considered saplings ( $\mathrm{Li}$ et al. 2014). From the census data for 4 years, the turnover time of saplings was calculated by following the procedure of Masaki et al. (2006). To analyze the processes of germination and settlement, in 2010 saplings were classified as being either at the "new sapling stage," comprising saplings recruited in the current year, or at the "old sapling stage," comprising saplings that had survived at least 1 year. All trees in the plot were divided into three growth stages: newborn sapling stage, old sapling stage, and canopy tree stage. 


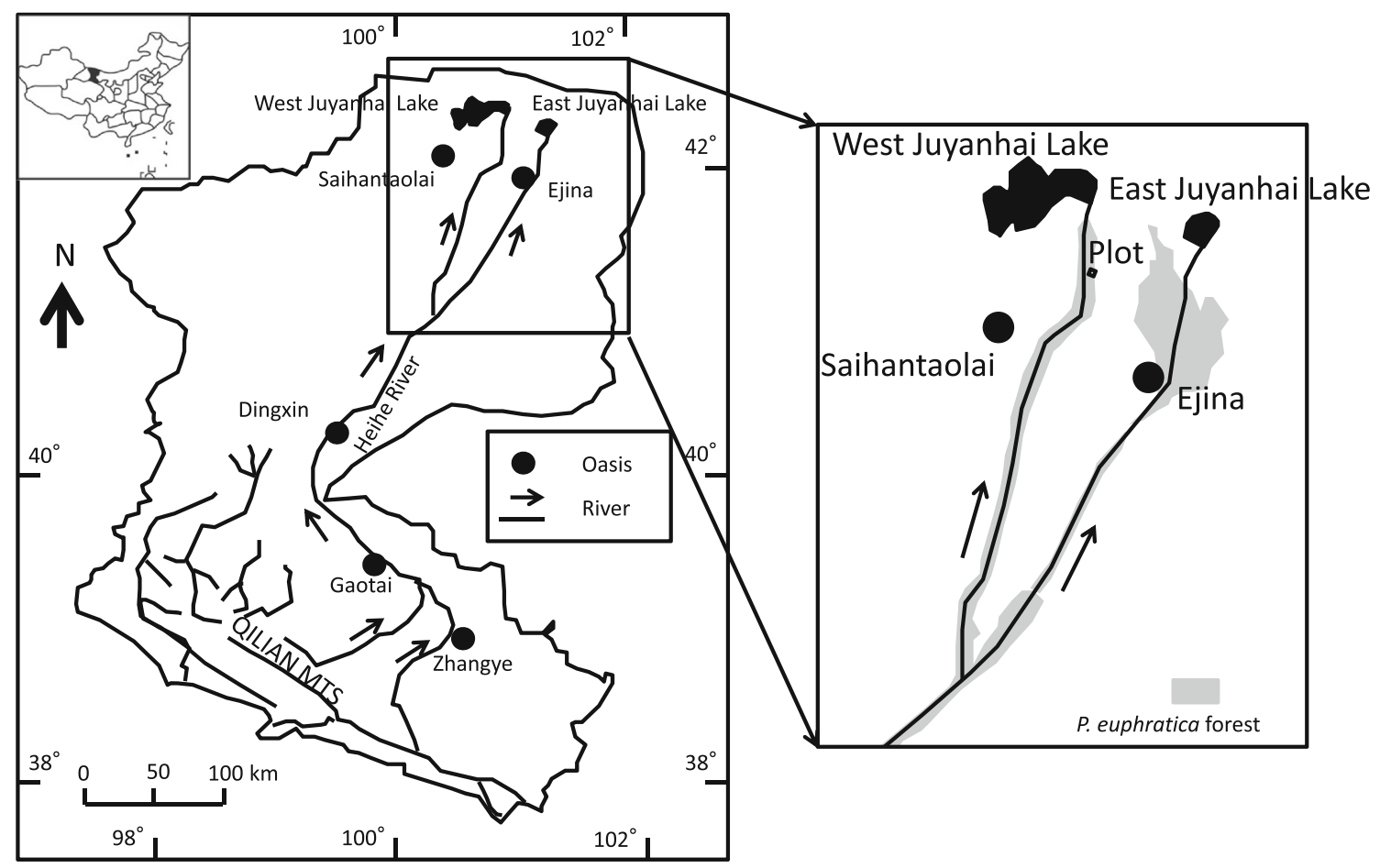

Fig. 1 Study area in northwestern China

\section{Annual birth rate and mortality rate}

The annual birth rate $(B)$ and mortality rate $(M)$ were calculated as:

$B(\%)=\left(n_{\text {bir }} / n_{\text {all }}\right) \times 100$

$M(\%)=\left(n_{\text {mor }} / n_{\text {all }}\right) \times 100$

where $n_{\text {bir }}$ is the number of newly recruited saplings in the current year, $n_{\text {mor }}$ is the number of saplings that died in the current year, and $n_{\text {all }}$ is the number of all saplings in the year before the current year.

\section{Turnover time}

Following Masaki et al. (2006), the turnover time was calculated. The average mortality rate $(D)$ is calculated as:

$D(\% /$ year $)=\ln \left(n_{1 \mathrm{st}} / n_{\text {sur }}\right) / y \times 100$

The average recruitment rate $(N)$ is calculated as

$$
N(\% / \text { year })=\ln \left(n_{\text {last }} / n_{\text {sur }}\right) / \mathrm{y} \times 100
$$

The turnover time $(T)$ is calculated as

$$
T(\text { year })=(1 / D+1 / N) / 2 \times 100
$$

Where $n_{1 \mathrm{st}}$ is the number of saplings in the first year of the study, $n_{\text {last }}$ is the number of all saplings in the last year of the study, $n_{\text {sur }}$ is the number of saplings surviving the first year in the last year of the study; and $y$ is the past years.

\section{Data analysis}

Normality tests to choose an appropriate correlation coefficient for the EC value and elevation were performed, and the correlation coefficient of the two variables was calculated using SPSS 17 (SPSS, Chicago, IL).

The regression analysis used to examine the relationship between net growth and dieback and initial height was performed using SAS 9.2 (SAS Institute, Cary, NC).

To analyze spatial associations among the three growth stages and two site conditions, EC values and the elevation of each subplot were classified into ten ranks by each $3 \mathrm{mS}$ $\mathrm{cm}^{-1}$ and eight ranks by each $4 \mathrm{~cm}$, respectively. The indices of local association $(X)$ (Perry and Dixon 2002) were calculated for each pair of variables. The $X$ value indicates positive and negative associations when $X>0$ and $X<0$, respectively. The statistical significance of the index was tested at $\alpha=0.05$ (Perry and Dixon 2002). The analysis was performed using the Spatial Analysis by Distance Indices (SADIE) software package available at http://home.cogeco.ca/ sadiespatial/index.html.

\section{Results}

\section{Site conditions}

Figure 2 shows the contour lines of ground elevations in the plot. Elevation varied by about $80 \mathrm{~cm}$. A shallow 


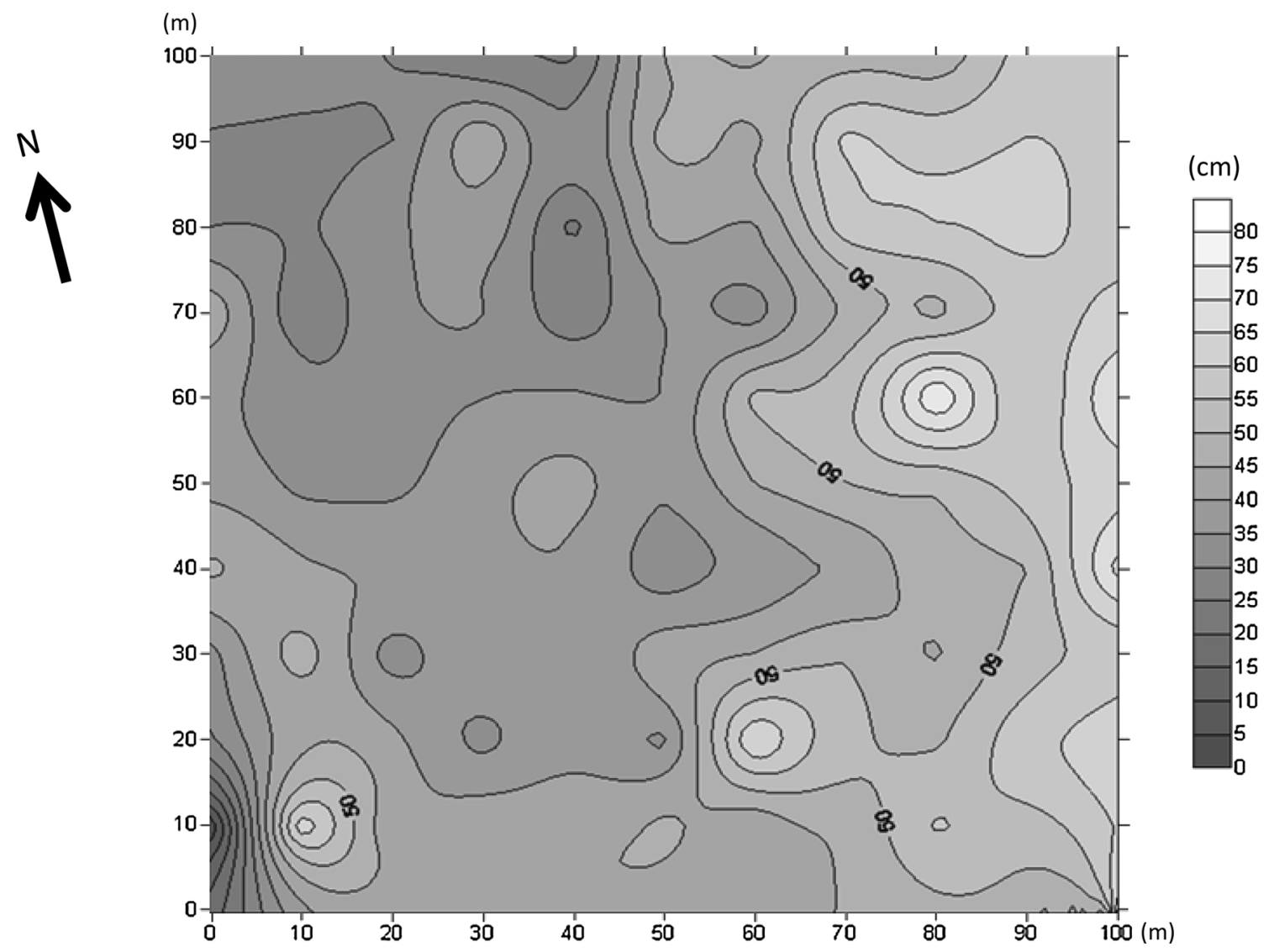

Fig. 2 Topography of the study site

riverbed ran from south to north in the western sector of the plot. The spatial change in topsoil salinity depicted in Fig. 3 indicates that the east side of the plot was saltiest. As the topsoil salinity data do not follow a normal distribution ( $P>0.05$ for elevation value, $P<0.05$ for EC value), Spearman's $\rho$ was calculated, which showed a significant positive association between them (Spearman's $\rho=0.492$, $P<0.01)$.

\section{Dynamics of saplings}

Figure 4 shows the frequency distributions of tree heights for four different cohorts, i.e., saplings older than 2009 and those recruited in 2010, 2011, and 2012. The height of most of the saplings ranged from 60 to $100 \mathrm{~cm}$. The mode of tree height frequency distribution of the cohort older than 2009 gradually moved from 60 to $100 \mathrm{~cm}$, while the distribution of those generated in 2010 and 2011 moved from 60 to $80 \mathrm{~cm}$, indicating that saplings gradually grew each year. However, fewer than $1 \%$ of saplings could reach the canopy level in the last 4 years, showing some restraining effects on $P$. euphratica saplings at 2-m height.

The annual birth rate was calculated using Eq. 1. In 2010-2011, roughly $30 \%$ of the saplings were new recruits; such a high rate of new entry in 1 year reflects vital, continuous regeneration activity, but the magnitude of new entry fluctuated widely from $9.4 \%$ (2011-2012) to $29.4 \%$ (2010-2011), indicating that germination was readily affected by environmental conditions. The annual mortality rate was calculated using Eq. 2. The mortality rate was stable at 20-30\% every year, indicating that saplings grow relatively steadily once settled.

From Eqs. 3-5, the turnover time, which represents the period during which the saplings persisted in the understory, was calculated to be 4 years. Through the experimental period, very few saplings $(<1 \%)$ made the transition from $2 \mathrm{~m}$ height to the canopy tree class (Fig. 4). Therefore, most saplings persisted for about 4 years in the understory before being replaced by new recruits.

The relationship between height growth and initial height is shown in Fig. 5. Height growth (including dieback) shows a negative trend with initial height. Smaller saplings did not show high survival rates but maintained greater positive height growth and grew into large saplings. In contrast, larger saplings did not grow well but maintained high survival rates.

Figure 6 shows the changes in the summed total height and density of saplings in the census years. Summed total 
(m)

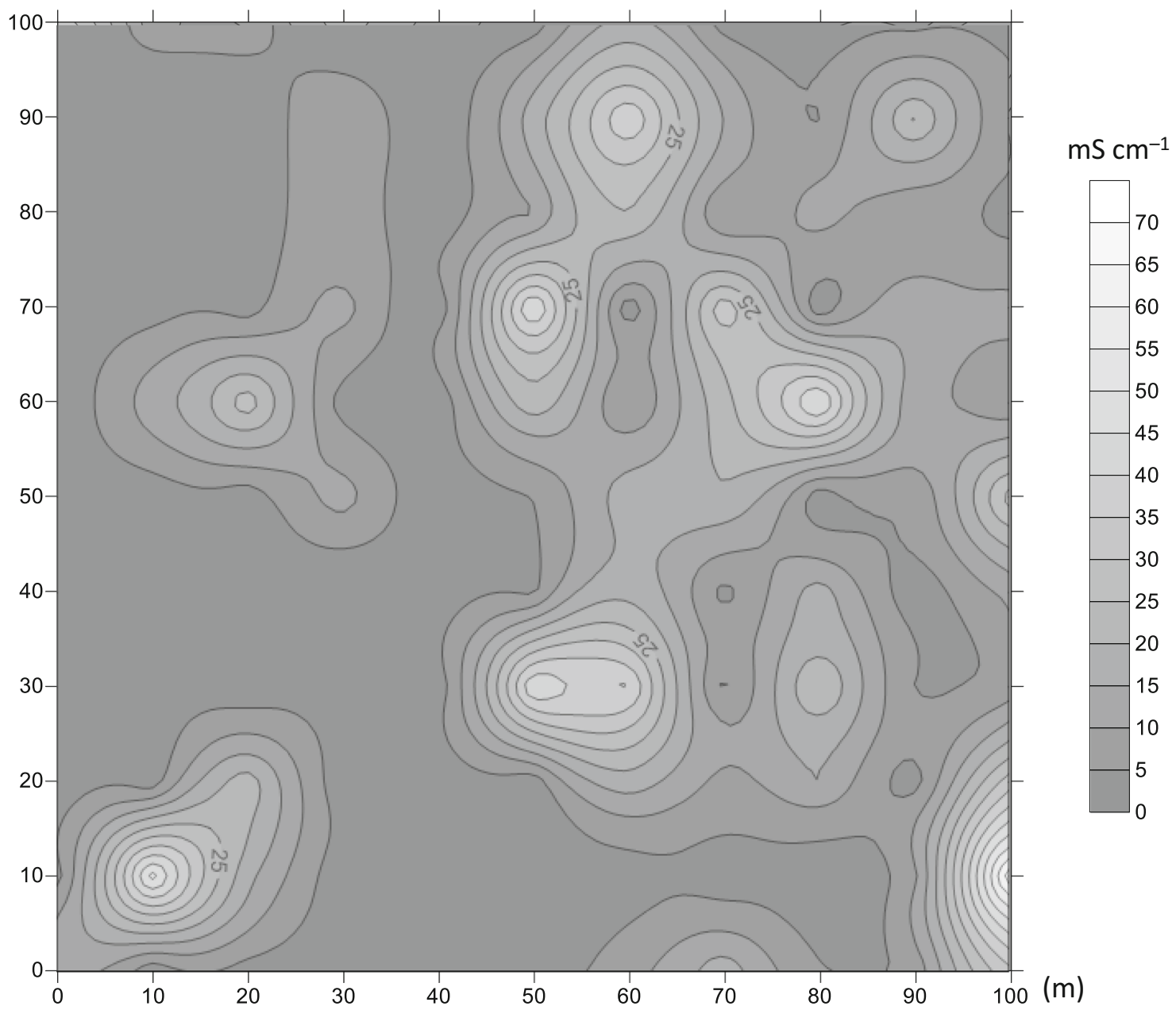

Fig. 3 Distribution of soil salinity; the geographic orientation matches Fig. 2

height increased from below $300 \mathrm{~m}$ in 2009 to almost $400 \mathrm{~m}$ in 2010, and was stable between 350 and $400 \mathrm{~m}$ from 2010 to 2012 . The density of saplings was almost constant over the 4 years.

\section{Spatial distributions and associations}

The spatial distributions of site conditions and trees in three different growth stages are presented in Fig. 7. A positive association was observed between elevation and topsoil salinity, and significant positive associations were also observed among all three tree growth stages (Table 1). Newly recruited saplings had positive associations with both elevation and topsoil salinity. The distributions of older saplings were positively associated with topsoil salinity but not elevation (Table 1). In contrast, those of canopy trees were positively associated with elevation but not topsoil salinity (Table 1).

\section{Discussion}

Flood events greatly affect environmental conditions and vegetation in arid regions. Floodwater can leach salt down from the topsoil layer (Salazar et al. 2014), which explains why the salinity of topsoil in the riverbed was lower than that of topsoil on the riverbank (Figs. 2, 3). Furthermore, salinity showed a positive association with ground elevation (Table 1). Flood water can also influence the germination of $P$. euphratica (Thevs et al. 2008). Suitable places for settlement of $P$. euphratica are restricted to certain limited site conditions along the river in a belt of the riverbank (Thevs et al. 2008; Fig. 7); therefore, newly generated saplings showed a positive association with ground elevation and topsoil salinity (Table 1). The distribution of older saplings was wider than that of newborn saplings in this study (Fig. 7), demonstrating that $P$. euphratica saplings are greatly affected by hydrological 


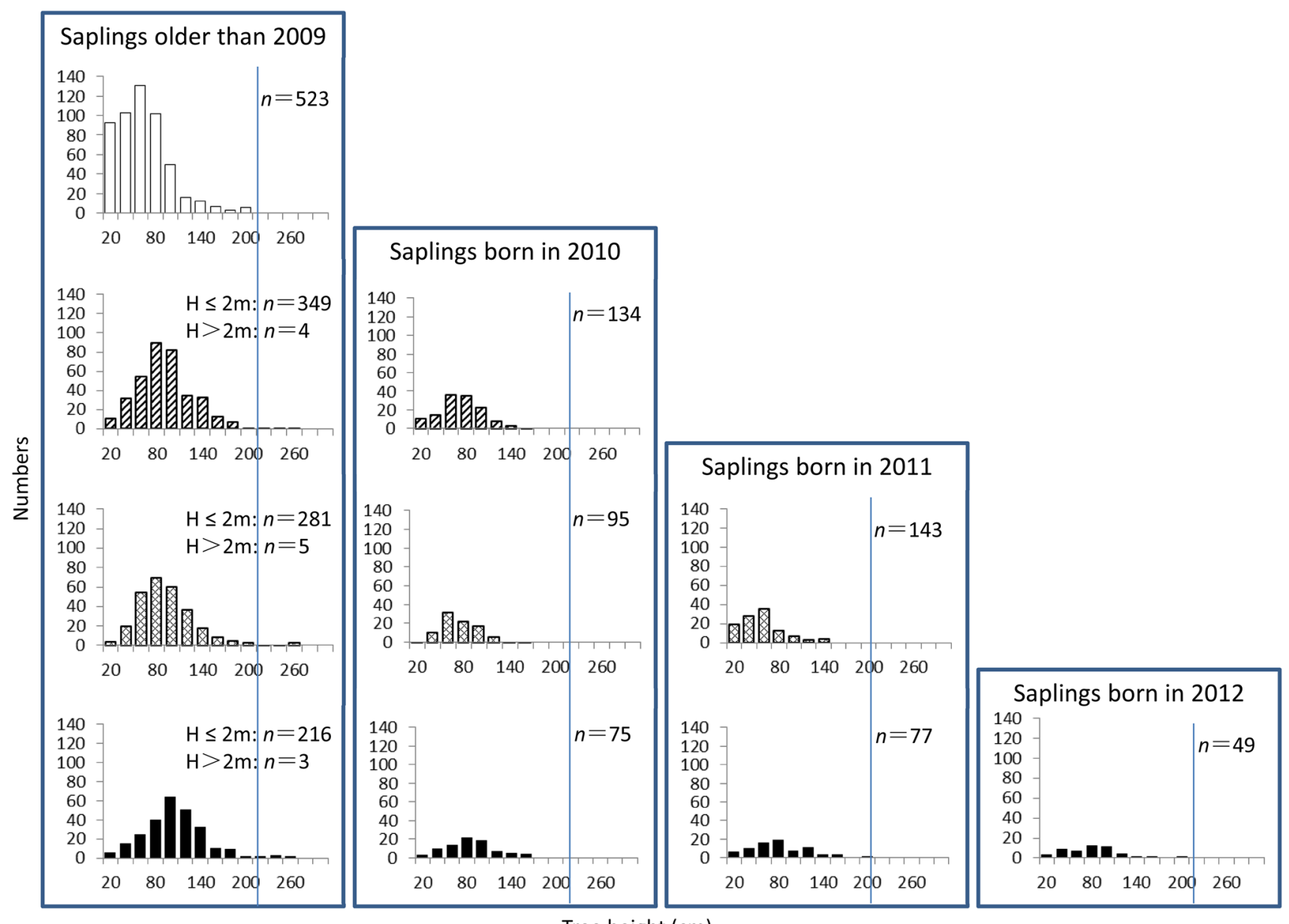

Tree height $(\mathrm{cm})$

Fig. 4 Changes in the frequency distribution of sapling height in four different cohorts: open bars 2009, hatched bars 2010, cross-hatched bars 2011, filled bars 2012

a $2009-2010$

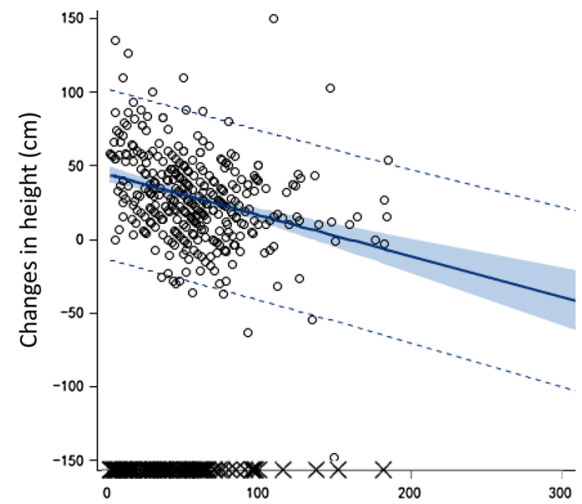

b $2010-2011$

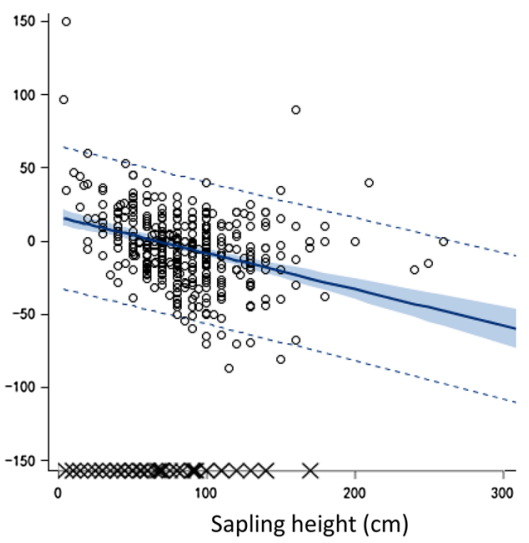

C $2011-2012$

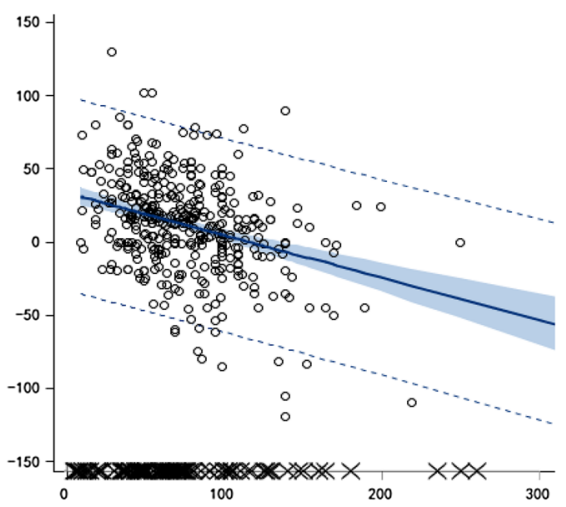

Fig. 5 Relationships between sapling growth in height and initial sapling height in three different time periods: a 2009-2010, b 2010-2011, c 2011-2012. Circles Net growth and dieback, crosses dead saplings, solid lines fit, shading $95 \%$ confidence limits, dashed lines $95 \%$ prediction limits 


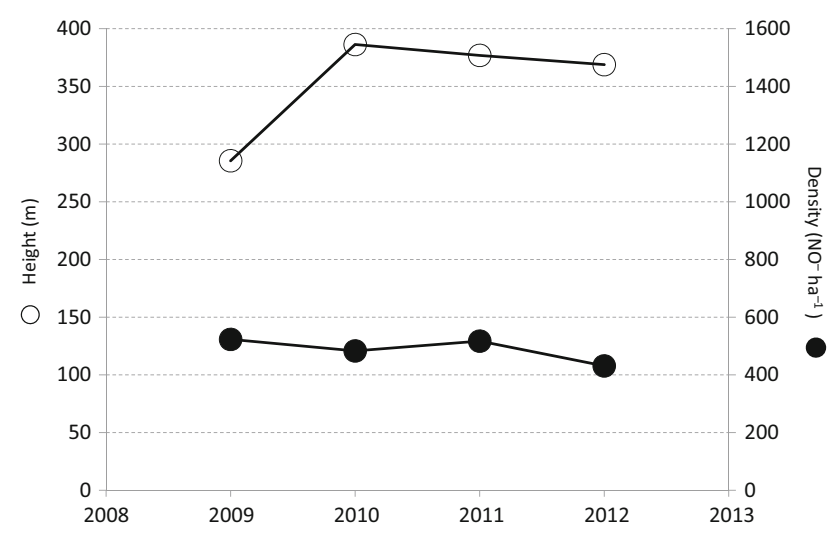

Fig. 6 Changes in summed total height and density of saplings over 4 years

dynamics; i.e., saplings will be distributed in higher locations when water levels are high and lower locations when levels are low. Thus, an independent association was observed between old saplings and elevation; however, a positive association indicated that saplings were also distributed in zones of high soil salinity. The distribution of saplings was determined by the fluctuation in water flow every year. Although most studies have pointed out that high levels of salt are detrimental to the growth of seedlings (Shumway and Bertness 1992; Xie et al. 2015), $P$. euphratica saplings adapt somewhat to salt stress (Shi et al. 2012) and soil salt concentration, provided that this is below a threshold value that allows life, allowing $P$. euphratica seedlings to settle and establish on land with relatively high soil salinity. However, less salt is better for photosynthesis and the accumulation of biomass ( $\mathrm{Li}$ et al. 2010), which facilitate $P$. euphratica growth so that they become canopy trees. Therefore, canopy trees tend to be distributed in soils where salt concentrations are lower than in the places where saplings grow and higher than in the riverbed. Consequently, canopy trees show independent associations with soil salinity. Hydrological events coupled with soil conditions may drive the distribution patterns of vegetation in riparian areas of arid regions.

To secure sustainable regeneration, it is important that a large number of young plants that can persist for years are maintained as a sapling bank on the forest floor, where they can await the occurrence of canopy gaps. In the $P$. euphratica forest that we studied, large numbers of saplings grew on the forest floor (Fig. 7). On average, saplings persisted for about 4 years, thereby allowing the formation of an effective sapling bank. Although few saplings $(<1 \%)$ in the sapling bank grew into the canopy tree class ( $>2 \mathrm{~m}$ tall; Fig. 4$)$, the stable densities and
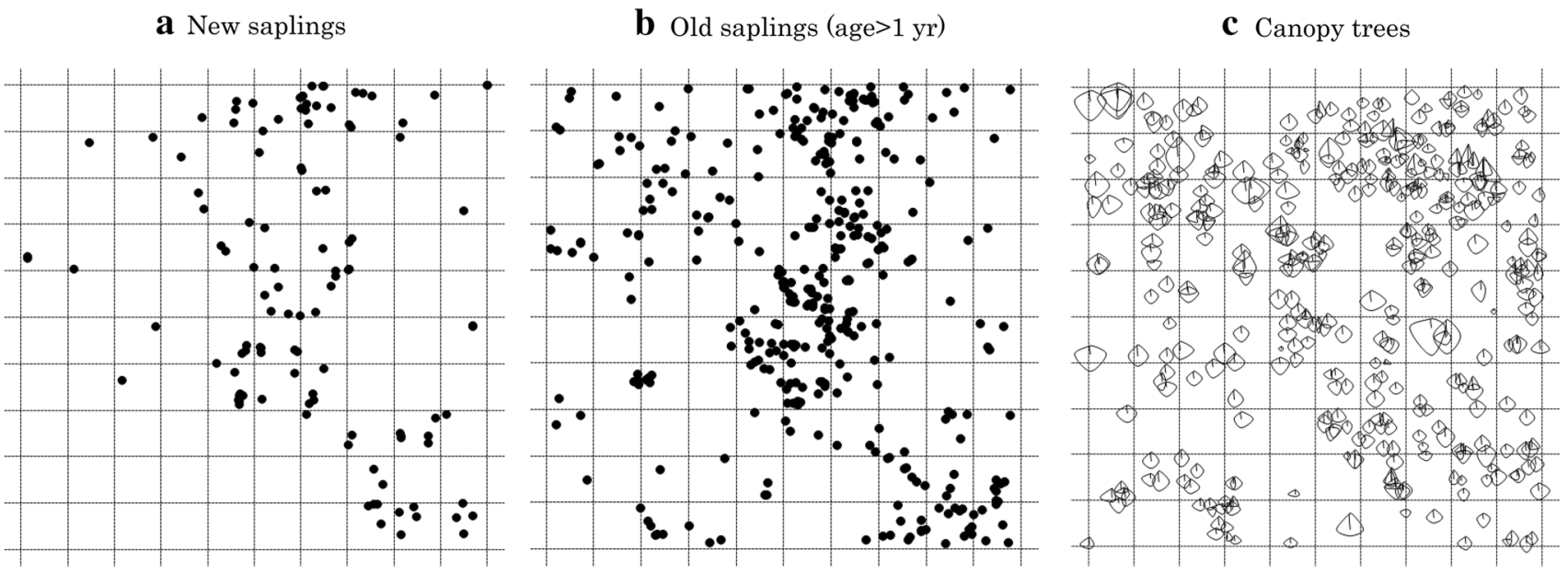

Fig. 7 Spatial distributions of a new saplings, $\mathbf{b}$ old saplings (age $>1$ year), $\mathbf{c}$ canopy trees in 2010 within the experimental plot

Table 1 Spatial associations in 2010

\begin{tabular}{lllll}
\hline & Old saplings & Newborn saplings & EC & Topography \\
\hline Canopy trees & $0.2759^{*}$ & $0.2294^{*}$ & 0.1009 & $0.3678^{*}$ \\
Old saplings & & $0.7517^{*}$ & $0.3067^{*}$ & 0.1602 \\
Newborn saplings & & & $0.4393^{*}$ & $0.3743^{*}$ \\
EC & & & $0.4663^{*}$ \\
\hline
\end{tabular}

Values are indices of association

* $P<0.05$ (significant positive association) $(\mathrm{X})$ 
heights of young individuals (Fig. 6) suggest that the sapling bank of $P$. euphratica can remain stable for a long time and thus allow regeneration. The existence of a sapling bank may guarantee the prompt replacement of canopy trees that die. This combination of demographic mechanisms indicates that the relationship between sapling mortality and growth (including new recruitment) is a regulator of $P$. euphratica forest dynamics.

The leaf area of $P$. euphratica is affected by partial defoliation of their distal parts (dieback) (Monda et al. 2008), which reduces their water consumption. However, not all saplings suffer dieback; each year, some grow well while others die back. In our experimental plot, larger saplings suffered dieback more often than smaller saplings; smaller saplings are sensitive to the various environments encountered and grow well even when the risk of mortality is high (Fig. 5), which results in most saplings being about 60-100 cm high (Fig. 4). Hence, saplings shorter than $60 \mathrm{~cm}$ grow easily but tend to die, while those taller than $100 \mathrm{~cm}$ are susceptible to dieback. The high rates of sapling loss and dieback in the sapling bank are balanced by vital new recruitment and growth each year. Dieback guarantees that saplings can live on the forest floor for many years and construct a sapling bank. New recruitment and growth balanced by sapling loss and dieback results in a stable sapling bank. Such mechanisms enable $P$. euphratica to regenerate in the unstable environment of arid areas.

\section{Conclusions}

In the Ejina Oasis, the dynamics of the Heihe River drive the distribution of environmental conditions and vegetation. The germination and establishment of $P$. euphratica saplings are greatly affected by river dynamics. Seed germination and sapling recruitment were limited to the riverbank, and yearly fluctuations in water flow increased the distribution area of saplings and constructed a sapling bank on the forest floor. This sapling bank guarantees (that) individual saplings escape certain disadvantages and survive for a long time. Annual growth is balanced by dieback and allows the species to maintain a stable state on the forest floor. This regeneration mechanism is adapted to the unstable environmental conditions in arid regions.

The amount of water supplied to the Ejina Oasis has declined annually because several reservoirs have been built in the middle reaches of the Heihe River to support a growing human population. In addition, residents have over-cultivated and overgrazed animals in these $P$. euphratica forests for many years. As a result, most of the $P$. euphratica forests in the Ejina Oasis have been negatively impacted and failed to regenerate either sexually or asexually (Cao et al. 2012). To restore $P$. euphratica forests in the Ejina Oasis, it is necessary to draw off water regularly from reservoirs in the middle reaches every year.

Acknowledgments This research was supported by the Introduction of Vegetation Natural Restoration Technology based on Soil Seed Banks (2009-4-29) and the Advanced Subject of Forestry Science Foundation (lxxk2015-03). We thank the Key Laboratory of Genetic Resources of Forest and Forest Protection of Hebei Province for its support.

Open Access This article is distributed under the terms of the Creative Commons Attribution 4.0 International License (http://crea tivecommons.org/licenses/by/4.0/), which permits unrestricted use, distribution, and reproduction in any medium, provided you give appropriate credit to the original author(s) and the source, provide a link to the Creative Commons license, and indicate if changes were made.

\section{References}

Barsoum N (2002) Relative contributions of sexual and asexual regeneration strategies in Populus nigra and Salix alba during the first years of establishment on a braided gravel bed river. Evol Ecol 15:255-279

Cao D, Li J, Huang Z, Baskin CC, Baskin JM, Hao P, Zhou W, Li J (2012) Reproductive characteristics of a Populus euphratica population and prospects for its restoration in China. PLoS One 7:e39121. doi:10.1371/journal.pone.0039121

D'Amato AW, Orwig DA, Foster DR (2009) Understory vegetation in old-growth and second-growth Tsuga Canadensis forests in western Massachusetts. For Ecol Manage 257(3):1043-1052

Gauthier S, Bernier P, Kuuluvainen T, Shvidenko AZ, Schepaschenko DG (2015) Boreal forest health and global change. Science 394:819-822

Haney JA, Turner DS, Springer AE, Stromberg JC, Stevens LE, Pearthree PA, Supplee V (2008) Ecological implications of Verde river flows. A report by the Verde river basin partnership, Arizona Water Institute and the Nature Conservancy. Available at http://azconservation.org

Hara M (1987) Analysis of seedling banks of a climax beech forest: ecological importance of seedling sprouts. Vegetatio 71:67-74

Hua P (2003) Studies on seed germination and seeding early growth of Populus euphratica on the flood plain. Environ Protect Xingjiang 25:14-17

Li X, Song Y, Nian F (2000) Characteristics of water transformation and its effects on environment in the arid region. Chin Geogr Sci 10:52-60

Li J, Zhao C, Yan Y, Li J, Sun D (2010) Effects of salt on the growth and photosynthetic characteristics of Populus euphratica seedlings. J Desert Res 30:80-86 (in Chinese with English abstract)

Li X, Li Y, Zhang G, Wang L, Yoshikawa K (2014) Dynamics of canopy tree of riparian forest, Populus euphratica, and their relationship with environmental conditions in Ejina Oasis, Inner Mongolia, China. J Arid Land Stud 24:17-20

Masaki T, Tanaka H, Shibata M (2006) Forest ecology, with longterm perspectives, 1st edn. Bun-ichi Sogo Shuppan, Tokyo (in Japanese)

Monda Y, Miki N, Yoshikawa K (2008) Stand structure and regeneration of Populus euphratica forest in the lower reaches of the Heihe River, NW China. Landsc Ecol Eng 4:115-124

Nyland RD, Bashant AL, Bohn KK, Verostek JM (2006) Interference to hardwood regeneration in northeastern North America: 
controlling effects of American beech, striped maple, and hobblebush. N J Appl For 23(2):122-132

Perry JN, Dixon P (2002) A new method to measure spatial association for ecological count data. Ecoscience 9:133-141

Salazar O, Vargas J, Nájera F, Seguel O, Casanova M (2014) Monitoring of nitrate leaching during flush flooding events in a coarse-textured floodplain soil. Agric Water Manage 146:218-227

Shi J, Wang X, Liu M (2012) Effects of $\mathrm{NaCl}$ stress on the physiological and biochemical indexes in seedling leaves of Populus euphratica Oliv. Xingjiang Agric Sci 49:2022-2028 (in Chinese with English abstract)

Shumway SW, Bertness MD (1992) Salt stress limitation of seedling recruitment in a salt marsh plant community. Oecologia 92:490-497

Thevs N, Zerbe S, Schnittler M, Abdusalih N, Succow M (2008) Structure, reproduction and flood-induce dynamics of riparian tugai forests at the Tarim River in Xinjiang, NW China. Forestry $81: 45-57$

Wen X, Wu Y, Su J, Zhang Y, Liu F (2005) Hydrochemical characteristics and salinity of groundwater in the Ejina Basin, Northwestern China. Environ Geol 48:665-675
Wiehle M, Eusemann P, Thevs N, Schnittler M (2009) Root suckering patterns in Populus euphratica (Euphrates poplar, Salicaceae). Trees 23:991-1001

Xie Z, Duan L, Li Z, Wang X, Liu X (2015) Dose-dependent effects of coronatine on cotton seedling growth under salt stress. J Plant Growth Regul 34:651-664

Zhang Y, Li J, Zhang H, Zhou D, Wu F, Cheng C, Li J, Li S (2005) Spatiotemporal patterns of seed dispersal in Populus euphratica. Acta Ecol Sin 25:1994-2000 (in Chinese)

Zhao W, Chang X, He Z (2004) Responses of distribution pattern of desert riparian forests to hydrologic process in Ejina oasis. Sci China Ser D Earth Sci 47:21-31

Zhao W, Chang X, He Z, Zhang Z (2007) Study on vegetation ecological water requirement in Ejina Oasis. Sci China Ser D Earth Sci 50:121-129

Zhu Y, Sang B, Chen Q, Liu K, Wu W, Chu F (2012) Rejuvenation techniques of P. euphratica forest in Hetian River basin. J S Agr 43:1544-1548 